\title{
Expert Meeting Report: HVAC Fault Detection, Diagnosis, and Repair/Replacement
}

David Springer

Alliance for Residential Building Innovation (ARBI) 


\section{NOTICE}

This report was prepared as an account of work sponsored by an agency of the United States government. Neither the United States government nor any agency thereof, nor any of their employees, subcontractors, or affiliated partners makes any warranty, express or implied, or assumes any legal liability or responsibility for the accuracy, completeness, or usefulness of any information, apparatus, product, or process disclosed, or represents that its use would not infringe privately owned rights. Reference herein to any specific commercial product, process, or service by trade name, trademark, manufacturer, or otherwise does not necessarily constitute or imply its endorsement, recommendation, or favoring by the United States government or any agency thereof. The views and opinions of authors expressed herein do not necessarily state or reflect those of the United States government or any agency thereof.

Available electronically at SciTech Connect http:/www.osti.gov/scitech

Available for a processing fee to U.S. Department of Energy and its contractors, in paper, from:

U.S. Department of Energy

Office of Scientific and Technical Information

P.O. Box 62

Oak Ridge, TN 37831-0062

OSTI http://www.osti.gov

Phone: 865.576 .8401

Fax: 865.576.5728

Email: reports@osti.gov

Available for sale to the public, in paper, from:

U.S. Department of Commerce

National Technical Information Service

5301 Shawnee Road

Alexandria, VA 22312

NTIS http://www.ntis.gov

Phone: 800.553 .6847 or 703.605 .6000

Fax: 703.605.6900

Email: orders@ntis.gov 


\title{
Expert Meeting Report: HVAC Fault Detection, Diagnosis, and Repair/Replacement
}

\author{
Prepared for: \\ The National Renewable Energy Laboratory \\ On behalf of the U.S. Department of Energy's Building America Program \\ Office of Energy Efficiency and Renewable Energy \\ 15013 Denver West Parkway \\ Golden, CO 80401 \\ NREL Contract No. DE-AC36-08GO28308
}

Prepared by:

David Springer

Alliance for Residential Building Innovation (ARBI)

Davis Energy Group, Team Lead

123 C Street

Davis, California 95616

NREL Technical Monitor: Michael Gestwick

Prepared under Subcontract No. KNDJ-0-40340-00

May 2016 
[This page left blank] 


\section{Contents}

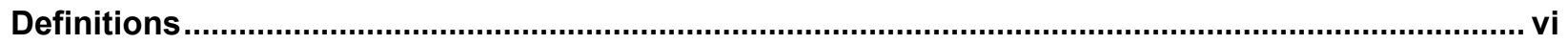

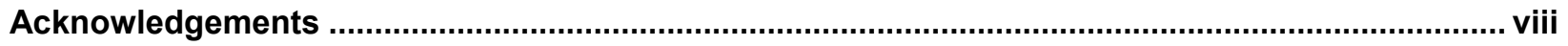

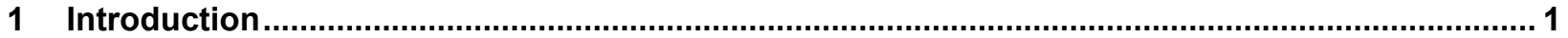

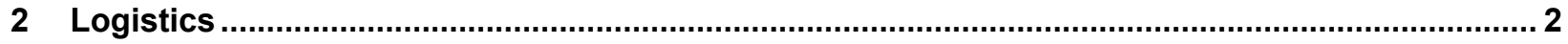

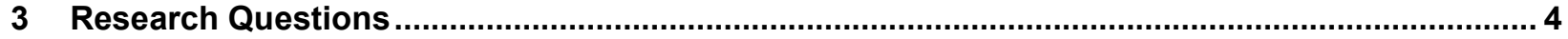

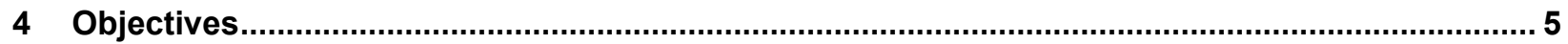

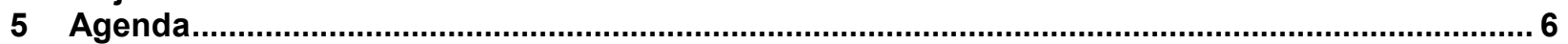

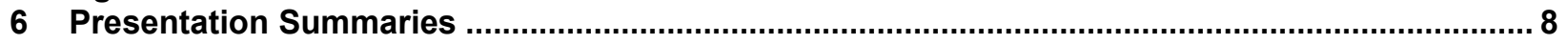

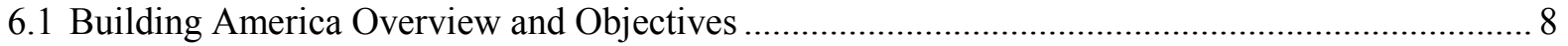

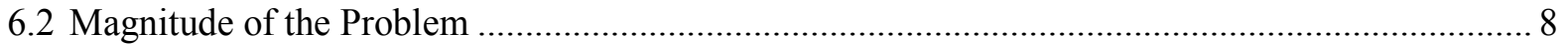

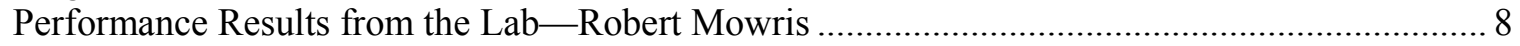

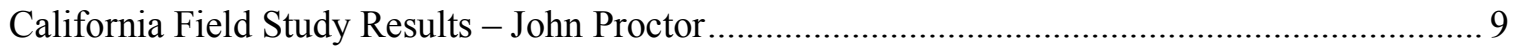

Measuring Faults and Their Effects - Jerine Ahmed............................................................... 9

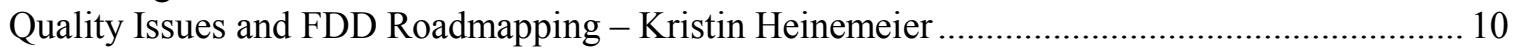

Reliability of Diagnostic Procedures - David Yuill ................................................................... 11

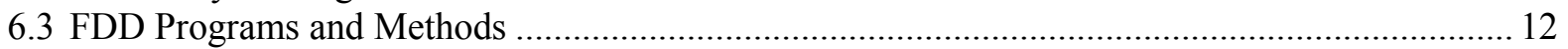

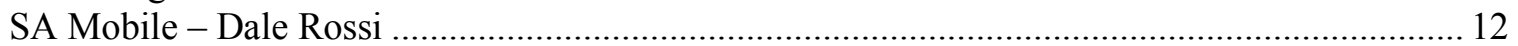

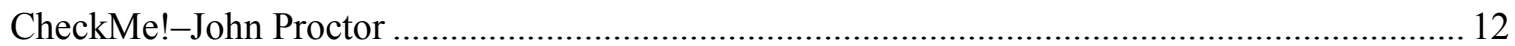

Retrofit Field Diagnostic Methods-David Springer ............................................................... 13

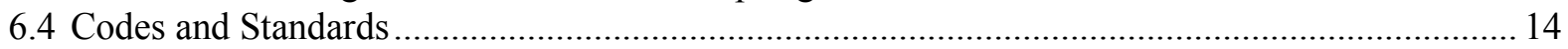

Application of ACCA Standards to Programs-Marshall Hunt .................................................... 14

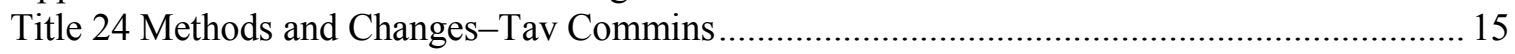

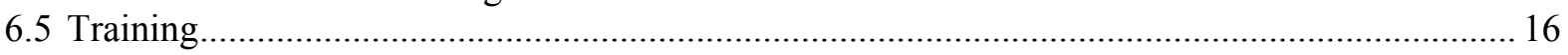

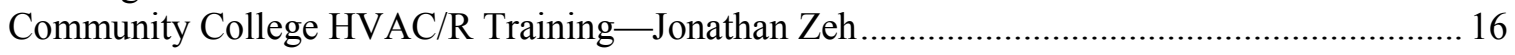

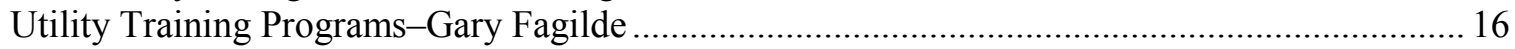

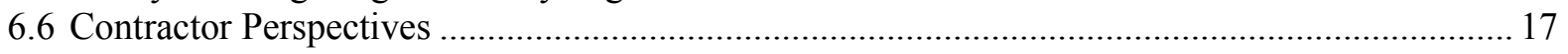

HVAC Contractors-Bob Radcliff....................................................................................... 17

Home Performance Contractors-Mike McFarland and Dan Perunko .......................................... 18

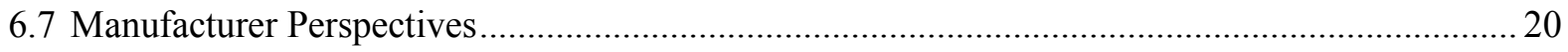

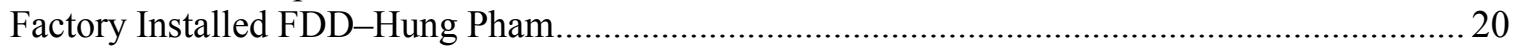

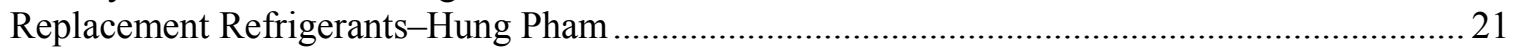

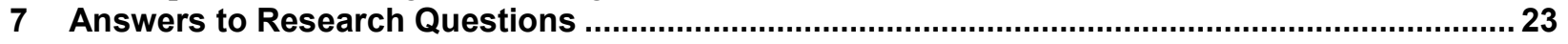

7.1 Is FDD Worth the Investment and what is the Savings Potential? ............................................. 23

7.2 How Effective are Available FDD Methods and what do they cost to Implement? ..................... 23

7.3 What Training is Needed for Effective FDD and is it Being Provided?..................................... 24

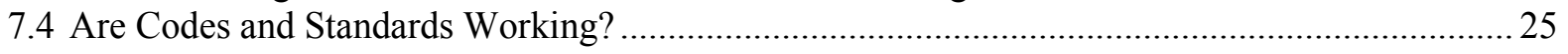

7.5 What are the Major gaps and how can they be Addressed?..................................................... 25

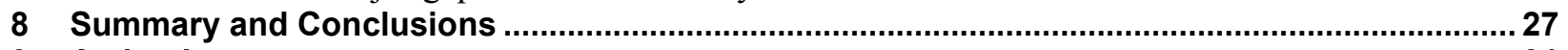

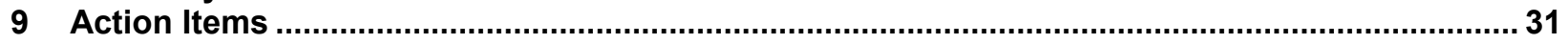

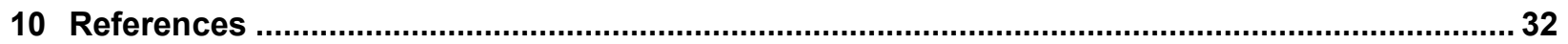

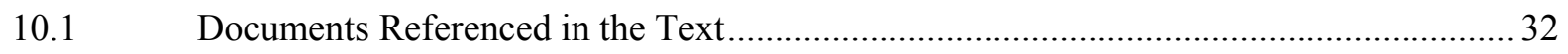

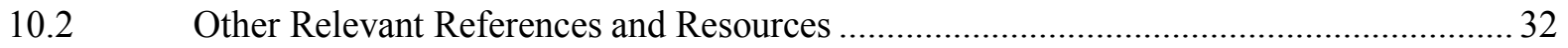




\section{Definitions}

ACCA

AFUE

AHRI

ARBI

BA-PIRC

CEC

CFM

CPUC

DDC

DEG

EEBA

EER

FDD

FDD \& R

GTI

GWP

HERS

HVAC

IT

$\mathrm{kWh}$

LBNL

LED

MMF
Air Conditioning Contractors of America

Annual fuel utilization efficiency

Air Conditioning, Heating and Refrigeration Institute

Alliance for Residential Building Innovation

Building America Partnership for Improved Residential Construction

California Energy Commission

Cubic feet per minute

California Public Utilities Commission

Direct digital control

Davis Energy Group

Energy and Environmental Building Alliance

Energy efficiency ratio

Fault detection and diagnostics

Fault detection diagnostics and repair/replacement

Gas Technology Institute

Global warming potential

Home Energy Rating System

Heating, ventilation, and air conditioning

Information technology

Kilowatt-hour

Lawrence Berkeley National Laboratory

Light emitting diode

Minimum marketable feature 
NATE

NIST

NREL

ODP

PG\&E

QI

QC

SCE

SDG\&E

SEER

SMACNA

TXV

w.c.

WCEC

WHPA
North American Technician Excellence

National Institute of Standards and Technology

National Renewable Energy Laboratory

Ozone depletion potential

Pacific Gas and Electric

Quality improvement

Quality control

Southern California Edison

San Diego Gas and Electric

Seasonal energy efficiency ratio

Sheet Metal and Air Conditioning Contractors' National Association

Thermal Expansion Valve

Water Column (in reference to pressure)

Western Cooling Efficiency Center

Western HVAC Performance Alliance 


\section{Acknowledgements}

The Alliance for Residential Building Innovation (ARBI) team is indebted to the speakers, listed below, who provided outstanding presentations and shared their valuable insights and experiences without reservation.

Jerine Ahmed, Southern California Edison

Tav Commins, California Energy Commission

Gary Fagilde, Pacific Gas \& Electric Company

Kristin Heinemeier, UC Davis Western Cooling Efficiency Center

Marshall Hunt, Pacific Gas \& Electric Company

Mike McFarland, EnergyDocs

Robert Mowris, Robert Mowris \& Associates

Dan Perunko, Balance Point Home Performance

Hung Pham, Emerson Climate Systems

John Proctor, Proctor Engineering

Bob Radcliff, Beutler Corporation

Dale Rossi, Field Diagnostic Services Inc.

David Springer, DEG/ARBI

David Yuill, Purdue University

Jonathan Zeh, Sacramento City College

Special thanks goes to Kristin Heinemeier and the UC Davis Western Cooling Efficiency Center, who provided the facilities and assisted with development of the invitation list and agenda. 


\section{Introduction}

Davis Energy Group (DEG) and the ARBI team became interested in fault detection and diagnosis (FDD) during work on a project sponsored by California utilities to review FDD research and program evaluation results and to investigate the role that measurement uncertainty can have on refrigerant charge verification (Hunt 2010). This experience led to the realization that there is a large missed opportunity in underperforming residential air conditioning systems and the recognition that trained home performance contractors have the skills to diagnose and, in some cases, correct major defects. If contractors are already onsite performing other related work such as duct testing, diagnostics can be completed at minimal additional expenditure of time. Upon researching available diagnostic methods, the ARBI team found that no systematic, stepby-step methods were available. To address this need, the team completed a project in 2012 to develop a Building America guideline for detecting and diagnosing airflow and refrigerant faults.

The concept for the expert meeting described in this report was to bring together most of the stakeholders in the area of FDD including academic researchers, manufacturers, educators, program managers and implementers, representatives of standards organizations, utilities, HVAC contractors, and home performance contractors to develop ideas to capitalize on the residential HVAC efficiency resource.

According to the California Residential Appliance Saturation Study (RASS 2009), air conditioning represents only $7 \%$ of residential energy use, but this sample includes homes that do not have air conditioners and those that are infrequently used in the mild marine climates. This percentage is much greater in the hot central valleys and desert areas of the state and air conditioning is responsible for more than half of California's residential peak load. Defects have an impact in all climates and take a larger toll on energy use in more humid climates where operating hours are longer. Motivations to correct defects include energy savings and improved comfort and indoor air quality for home occupants; reduced peak load imposed on the generation, transmission, and distribution network; reduced carbon emissions; and conservation of energy resources.

The Building America Program prioritizes research goals and establishes milestones. This expert meeting responded to the following milestones:

- In 2014, investigate viability of large-scale adoption and implementation of HVAC tuneup at community scale, including potential for utility participation and consumer incentives.

- In 2015, demonstrate market-ready space conditioning equipment that delivers $30 \%$ cooling energy savings relative to current forced air seasonal energy efficiency ratio (SEER) 16 systems while delivering Building America best practices in new and existing low-load homes.

- In 2015, document new construction community-scale adoption of space conditioning distribution system solutions that ensure negligible conductive, radiant, and leakage losses in new and existing low-load homes. 


\section{Logistics}

The meeting was held in Davis, California, on September 10, 2013, at the UC Davis Energy Efficiency Center, 1605 Tilia Street, Suite 100. The meeting started at 10:00 AM and was scheduled to end at 5:00 PM, but discussions continued until about 5:30 PM.

A complete list of attendees, including speakers, is provided below.

\begin{tabular}{|c|c|c|c|}
\hline First & Last & Affiliation & Email \\
\hline Jerine & Ahmed & Southern California Edison & Jerine.Ahmed@sce.com \\
\hline Mark & Berman & Davis Energy Group & mjberm@davisenergy.com \\
\hline Larry & Brand & Gas Technology Institute & larry.brand@gastechnology.org \\
\hline Catherine & Chapell & TRC & cchappell@trcsolutions.com \\
\hline Mark & Cherniak & New Buildings Institute & markc@newbuildings.org \\
\hline Tav & Commins & California Energy Commission & tcommins@energy.ca.gov \\
\hline Roy & Crawford & University of Texas, Tyler & rcrawford@uttyler.edu \\
\hline Piotr & Domanski & NIST & piotr.domanski@nist.gov \\
\hline John & Douglas & Lennox & jon.douglas@lennoxind.com \\
\hline Eric & Emblem & SMACNA & eemblem@gmail.com \\
\hline Gary & Fagilde & Pacific Gas \& Electric Company & GAF5@pge.com \\
\hline Alea & German & DEG & agerman@davisenergy.com \\
\hline Kristin & Heinemeier & WCEC & kheinemeier@ucdavis.edu \\
\hline Marshall & Hunt & PG\&E & mbh9@pge.com \\
\hline Matthew & Irons & Emerson & matthew.irons@emerson.com \\
\hline Mike & Lubliner & WSU & LublinerM@energy.wsu.edu \\
\hline Mike & McFarland & EnergyDocs & Mike@EnergyDocs.net \\
\hline Jon & McHugh & McHugh Energy & jon@mchughenergy.com \\
\hline Josh & McNeil & Davis Energy Group & imcneil@davisenergy.com \\
\hline Jennifer & McWilliams & KEMA & jennifer.mcwilliams@dnvkema.com \\
\hline Mardelle & Moreno-Wilbur & Davis Energy Group & mmwilbur@davisenergy.com \\
\hline Robert & Mowris & Robert Mowris \& Associates & robert.mowris@verified-rca.com \\
\hline Dan & Perunko & Balance Point Home Performance & dan@balancepointhp.com \\
\hline Hung & Pham & Emerson Climate Systems & Hung.M.Pham@emerson.com \\
\hline John & Proctor & Proctor Engineering & john@proctoreng.com \\
\hline Bob & Radcliff & Beutler Corporation & radcliffb@beutlercorp.com \\
\hline Jeremy & Reefe & SDG\&E & imreefe@semprautilities.com \\
\hline Dale & Rossi & Field Diagnostic Systems Inc. & dtrossi@fielddiagnostics.com \\
\hline David & Springer & Davis Energy Group & springer@davisenergy.com \\
\hline John & Stoops & KEMA & john.stoops@kema.com \\
\hline Nils & Strindberg & $\begin{array}{l}\text { California Public Utilities } \\
\text { Commission }\end{array}$ & nils.strindberg@cpuc.ca.gov \\
\hline $\operatorname{lan}$ & Walker & LBNL & IsWalker@lbl.gov \\
\hline
\end{tabular}


\begin{tabular}{l|l} 
u.s. Department of & Energy Efficiency \& \\
ENERCY & Renewable Energy
\end{tabular}

\begin{tabular}{|l|l|l|l|} 
Beth & Weitzel & Davis Energy Group & eweitzel@davisenergy.com \\
\hline Brad & Williams & Beutler Corp & williamsb@beutlercorp.com \\
\hline John & Winkler & NREL & Jon.Winkler@nrel.gov \\
\hline Craig & Wray & LBNL & $\underline{\text { cpwray@lbl.gov }}$ \\
\hline David & Yuill & Purdue & $\underline{\text { dyuill@purdue.edu }}$ \\
\hline Jonathan & Zeh & Sacramento City College & zehj@scc.losrios.edu \\
\hline
\end{tabular}




\section{Research Questions}

To help frame the discussion, the following key research questions were presented in the meeting overview:

- Is FDD worth the investment, and what is the savings potential?

- How effective are available FDD methods and what do they cost to implement?

- What training is needed for effective FDD and is it being provided?

- Are codes and standards working?

- What are the major gaps and how can they be addressed? 


\section{Objectives}

To take maximum advantage of the broad range of experience represented by the presenters and attendees it was important to clearly identify the meeting objectives, which were as follows:

- Review laboratory and field research results to identify the magnitude of the problem and potential areas to target

- Learn what FDD and replacement practices are currently applied by HVAC and home performance contractors and where they see the problems

- Identify and discuss key areas that need to be addressed, including:

○ Programmatic approaches

- Codes and standards

- Training and quality assurance.

The agenda was structured to address each of these areas, as well as to respond to the research questions. In an effort to provide further focus, the scope of the meeting was limited to the following:

- System Types-new and existing residential only

- Air conditioners

○ Heat pumps

○ Furnaces and air handlers

- Fault Types

○ Low airflow

- Refrigerant system charge, restrictions, and contaminants

- Mechanical and electrical faults and faulty installation

- Repair vs. Replacement Issues

○ Cost-effectiveness of FDD

- Replacement refrigerants for R-22

- Human Factors

$\circ$ Training and quality of maintenance

○ Homeowner knowledge and expectations. 


\section{Agenda}

The meeting agenda is provided below. Ten minutes were allotted for questions and answers and discussion following each section.

\section{0:00AM: Introductions and Logistics}

10:15 AM: Building America Overview and Meeting Objectives - David Springer, Davis Energy Group/ARBI

Overall program goal and expert meeting objectives

Research questions to be addressed

Related Building America activities

Dissemination of meeting outcomes - Building America Solution Center

\section{0:30 AM: Magnitude of the Problem}

Performance results from the lab: Robert Mowris, Robert Mowris \& Associates

California field survey results: John Proctor, Proctor Engineering

Measuring faults and their effects: Jerine Ahmed, Southern California Edison

Quality of service issues and FDD road mapping: Kristin Heinemeier, Western Cooling Efficiency Center

Reliability of diagnostic procedures and measurement accuracy: David Yuill, Purdue

\section{2:20 PM: Lunch}

12:50 PM: FDD Programs and Methods: What do they cover, how effective are they, and what is their potential to penetrate the market?

SA Mobile: Dale Rossi, Field Diagnostics Inc.

CheckMe!: John Proctor, Proctor Engineering

Retrofit field diagnostic methods: David Springer, DEG / ARBI

\section{1:50 PM: Codes and Standards}

ACCA Standards 4, 5 and 9 overview and code issues-Marshall Hunt, PG\&E

Title 24 requirements, quality installation, and compliance-Tav Commins, California Energy Commission

\section{2:35 PM: Break}

\section{2:50 PM: Training}

Community college programs_-Jonathan Zeh, Sacramento City College

Utility programs - Gary Fagilde, PG\&E 


\section{3:30 PM: The Contractor Perspective -Is there a business model for FDD?}

HVAC contractors: Bob Radcliff, Beutler Corp.

Home performance contractors: Mike McFarland, Energy Docs and Dan Perunko, Balance Point Home Performance

\section{4:00 PM: Break}

\section{4:15 PM: The Manufacturer's Perspective}

Factory installed FDD: Hung M. Pham, Emerson Climate Technologies

Replacement refrigerants: Hung M. Fan, Emerson Climate Technologies

\section{4:35 PM: Technical Discussion - Repair or Replace?}

\section{4:45 PM: Wrap-up}

Are there defined answers to the research questions; what are they?

Which of the ideas that have been discussed have merit?

What issues is there agreement on, and for which is there no agreement?

What have we missed?

Other resources. 


\section{Presentation Summaries}

This section includes brief summaries of each presentation. A review of discussions on topics covered by each section is also provided. Where PowerPoint presentations were made, links to those presentations are provided. An audio recording of most of the presentations is also available.

\subsection{Building America Overview and Objectives}

David Springer welcomed the speakers and attendees, provided a brief overview of the Building America Program, and listed the research questions, objectives, and intended scope of the meeting.

View the presentation: $\underline{\text { Introduction }}$

\subsection{Magnitude of the Problem}

\section{Performance Results from the Lab-Robert Mowris}

Robert reviewed results from lab testing to assess the impact of various faults (Mowris 2012). Tests were completed at Intertek using a 13 SEER 3-ton split system with R-22 refrigerant. Three chambers were employed to provide separate environmental conditions for evaporator entering air, the condensing unit, and attic ducts and equipment. Tests applied standard AHRI methods. The tests were designed to determine the impacts on efficiency and capacity of a variety of conditions, including:

- Uninsulated thermal expansion valve (TXV) sensing bulb

- Low airflow

- Ducts/equipment in a hot $\left(118^{\circ} \mathrm{F}\right)$ attic

- Evaporator coil blockage

- Duct leakage

- Condenser coil blockage

- Improper refrigerant charge

- Non-condensables

- Restrictions.

Some of the more compelling findings of these tests included:

- Airflow of $250 \mathrm{cfm} /$ ton reduced energy efficiency ratio (EER)* by $12 \%$ and has the potential to produce a false overcharge diagnostic due to freezing of the coil (the asterisk denotes an unofficial EER)

- Only $0.3 \%$ Nitrogen in the refrigerant reduced the EER* by $18 \%$ with no TXV and $12 \%$ for the TXV-equipped system

- Liquid line restrictions (e.g. due to clogged filter-dryer or metering devices) reduced EER* by $30 \%$ to $36 \%$ for non-TXV and TXV systems respectively 
- Multiple conditions that are commonly seen in existing homes, including $25 \%$ low airflow, ducts and air handler in a hot attic, 10\% undercharge, 30\% duct leakage, and $50 \%$ condenser coil blockage reduced the EER* by $54 \%$ and the SEER* by $67 \%$.

Robert explained shortcomings of California Title 24 charge verification methods, which only measure superheat (for non-TXV) and sub-cooling (for TXV) systems, and ACCA Standard 4, for which only $3 \%$ of the procedures are related to energy performance. He also pointed out how improperly maintained vacuum pumps, test instrument error, and poor service practices such as use of rules of thumb contribute to the introduction of non-condensables, improper charge, and other faults.

View the presentation: Laboratory Measurements of Residential HVAC Installation and Maintenance Faults

\section{California Field Study Results - John Proctor}

To develop a case for making improvements to California's Title 24 standards, John worked with a team to inspect a large number of recently built homes to identify HVAC installation and performance issues. He began his presentation by defining an "incremental effectiveness ratio" that divides benefits of maintenance by the incremental cost to diagnose, repair, and ensure quality, which is fundamental to the question of the value of HVAC service. He proceeded to show a series of graphs from his experience and other studies that illustrate the deviations from the ideal for airflow, charge, duct leakage and efficiency, and non-condensables, as well as the incidence of occurrence of these defects.

For example, his graphs show a $50 \%$ reduction in airflow reduces EER by $25 \%$. A refrigerant charge that is $70 \%$ of the recommended charge reduces EER by about $55 \%$. Leaving Nitrogen in the line set and coil at 20 psig before charging with refrigerant reduces the sensible EER by about $45 \%$. From his 2003 survey, more than $60 \%$ of the houses checked failed on refrigerant charge, airflow, and duct leakage, and more than $95 \%$ failed overall.

California field studies show that energy standards have had a significant impact in reducing duct loss to an average of about $6 \%$ of cooling airflow. More data are needed to determine the magnitude of problems, particularly the presence of non-condensables, which can lead to misdiagnosis. An interesting observation that John made is that technicians find a lot more faults in systems if they are paid to find them than if they are just paid to test them.

View the presentation: What is at Stake? And What Can We Do?

\section{Measuring Faults and Their Effects - Jerine Ahmed}

Jerine explained that Goal 4 of the California Long Term Strategic Plan includes development of standards and guidelines for on-board and field diagnostics. He described the role of Southern California Edison (SCE) in identifying policy drivers, and their participation in the development of Title 24 standards, their work with the California Emerging Technologies Coordinating Council, and in supporting the development of the Western HVAC Performance Alliance (WHPA) FDD Roadmap.

SCE has completed several research projects (SCE 2012a, 2012b, 2013) that relate to development of FDD test methods and tools, and evaluating the impact of common faults. These 
reports are available on the Emerging Technologies Coordinating Council web site at www.etccca.com/ (search key word "fault detection").

Jerine noted there are about 13 million residential units in California using billions of $\mathrm{kWh}$. He indicated SCE's interest is in being more proactive rather than reactive, and in moving beyond studies and getting to reality. They identified the need for a tool to calibrate test methods, and worked with an advisory group to develop the scope. The FDD tool that was developed was used in the laboratory to identify faults.

To evaluate the impact of common faults, SCE used a 3-ton split system air conditioner running R-410a refrigerant. They conducted similar tests as those described by Robert Mowris, applying AHRI standard conditions. Efficiency degradations determined in the fault analysis included:

Low charge: Up to $60 \%$

Low airflow: Up to $40 \%$

Low charge and non-condensables: Up to $95 \%$

Low charge and reduced airflow: Up to $92 \%$

View presentation: Measuring Residential HVAC Faults and Their Effects

\section{Quality Issues and FDD Roadmapping - Kristin Heinemeier}

Kristin first described a technician observation study conducted by the Western Cooling Efficiency Center (WCEC) to assess the performance of contractors who were called on to inspect a residential system that had an induced fault (reversed heating/cooling control wiring). Thirteen contractors participated, and their performance was observed by a master HVAC technician and a social scientist. None of the technicians completed all tasks satisfactorily and one technician completed none of the requested tasks. None of the technicians correctly assessed refrigerant charge.

Kristin next addressed the question of homeowner perceptions of their HVAC systems to test the hypothesis that, as a consequence of people not understanding the complexity of systems, they are unwilling to pay to have them maintained as they would to have their car maintained. A consumer survey conducted by WCEC found that respondents view air conditioners as low tech, low maintenance, ugly, and environmentally unfriendly money wasters. By contrast, they view cars as attractive, high tech, high maintenance, but exciting possessions.

Another matter that affects how systems are maintained is the accuracy of instrumentation. Kristin presented results from a prior study by DEG and WCEC that looked at measurement uncertainty and found that measurements using standard acceptable methods can vary significantly from recommended tolerances. (This finding corresponds with similar observations by Robert Mowris and Robert Davis of PG\&E.) WCEC is in the process of evaluating test equipment using a condensing unit set up in their lab.

Kristin pointed out that there can be a requirement for automated FDD systems to be installed, but there is no way to know if they are working. She is involved in the development of standards for testing FDD systems. 
Lastly, Kristin reviewed the activities of the WHPA and described their Onboard and In-Field Fault Detection and Diagnostics Roadmap, which is aimed at resolving these problems.

View the presentation: Quality Issues and FDD Roadmapping

\section{Reliability of Diagnostic Procedures - David Yuill}

David's presentation spoke to the reliability of FDD procedures as applied to unitary air conditioners, and described the research conducted at Purdue led by Jim Braun. He focused on an FDD evaluation methodology, case study results, and future plans. The focus of Purdue's research is on evaluating the FDD protocol as opposed to instrument error. A large number (785) of individual lab tests were used to generate inputs for their analysis. Diagnoses were compared with known conditions to assess the protocols, and results were categorized as: no response, correct diagnosis, false alarm, misdiagnosis, missed detection, or detection with no diagnosis.

David and his team used the California Title 24 protocol as an example, which measures ambient, return air dry bulb, return air wet bulb, and supply air temperatures, as well as suction superheat, sub-cooling, and manufacturer's target sub-cooling. The analysis only looked at charge and airflow faults. Results varied depending on a defined "fault impact ratio" (FIR), but in the range of $85 \%-95 \%$ FIR the "no response" rate was $21 \%$, the "false alarm" rate was $50 \%$, the "misdiagnosis" rate was 20\%-30\%, and the "missed detection" rate was $30 \%-40 \%$. Since charts they developed are difficult even for experts to understand, they are moving to cost-based performance metrics that are more understandable.

David indicated that software developed at Purdue (FDD Evaluator 0.1.1) is available for download at no cost from http://tinyurl.com/FDDeval.

View the presentation: Reliability of Diagnostic Procedures: Evaluating the Performance of FDD Protocols Applied to Unitary Air-conditioning Equipment

\section{Discussion:}

With respect to the importance of accurate field instruments, there was discussion of the need for public disclosure of results of comparative tests that list the accuracy of instruments, including refrigerant manifold gauges and temperature and relative humidity/wet bulb devices. The possibility that analog manifold gauges should be prohibited for use in maintenance programs and Title 24 verification was also discussed.

Detection of non-condensables is a significant problem due to the high cost of equipment needed to evaluate refrigerant composition. Robert Mowris pointed out that such equipment is commonly used in the automotive industry for R-134a, but is not readily available for R-22 and R-410a.

Reacting to David Yuill's comment that systems are misdiagnosed about one third of the time, John Proctor pointed out that Title 24 has been assuming airflow is correct, will be requiring verification under the 2013 standards, and that it is likely that contractors will set the proper charge most of the time (also HERS verified), so his results don't apply. David responded that half the time technicians will get a false alarm even if sensors are working right, but John disagreed. David agreed it's difficult to know what fault prevalence is present in the real world. 
Kristin Heinemeier raised the point that we don't know if FDD really works. She is working with the WHPA to develop a standard for evaluating systems.

Hung Pham noted that these findings are consistent with what Emerson has seen. He noted that service techs don't want to touch evaporators because they are too difficult to access and require the removal of lots of screws. They don't want to take more than one hour for their diagnosis. His opinion is that service agreements are the way to go. There is a disconnect in the value chain: the skill set exists, but how can cost-effectiveness be defined? Managers won't allow technicians to take the needed time. John Proctor observed that those systems that are most likely to be off are those that are under service agreements; it may be best not to touch them.

Some discussion followed about the need to share data from laboratory and field tests.

\subsection{FDD Programs and Methods SA Mobile - Dale Rossi}

Dale began by describing that refrigeration cycle diagnostics is a complicated problem that has taken many years for them to address. He pointed out that an IT tool is required to achieve consistent results and has the added advantage of estimating efficiency and capacity. Using "Service Assistant" software, the SA Mobile system displays all information on an Androidbased mobile device.

Dale emphasized that achieving a quality result takes time, and that automation reduces the amount of time required to diagnose systems. He presented case studies of ten California homes that produced average annual savings of $310 \mathrm{kWh}$ per ton. He pointed out that computerized tools are the obvious stepping stones to on-board FDD.

View the presentation: Refrigeration Cycle Fault Detection and Diagnostics

\section{CheckMe!-John Proctor}

John shared some valuable information from his experiences running the CheckMe! program, which he began developing more than 20 years ago. CheckMe! uses a combination of diagnostic tools and other techniques to ensure quality and measurable improvements in performance. He drew a direct correlation between quality assurance and program success, citing the following ingredients as critical to QA:

- Technician training and acceptance

- Measurement accuracy

- Concentration on faults that make a difference (don't waste time trying to capture less than a 5\% improvement in efficiency)

- Technician correction (if technicians fail to improve, eliminate them)

- Reporting, feedback, and immediate support

- Continuous interaction at many levels

- Inspections

- Continuous evaluation. 
As an example that training and certification are not enough, he described a double-blind test comparing results of duct test and seal and refrigerant test jobs that are completed by both North America Technician Excellence (NATE) certified technicians and relatively untrained technicians. The NATE-trained techs performed only marginally better than the non-certified techs.

John cited the following as being the major barriers to effective FDD and replacement efforts:

- Contractors don’t need to improve their practices to make money

- The market is based on least cost and some services are based on piece rate

- There is little or no technician oversight; supervisors and business owners frequently have less technical knowledge than technicians

- Rhetoric without performance-advertised qualifications do not assure performance.

View the presentation: What is at Stake? And What Does CheckMe! Do?

\section{Retrofit Field Diagnostic Methods-David Springer}

David concentrated his presentation on the cost-effectiveness of field diagnostics, training that is needed to find and mitigate the major defects, and whether there is a good business model for quality HVAC maintenance. He identified airflow as being a major performance issue, and presented simple diagnostic methods that can be applied by contractors trained in home performance to (1) diagnose the source of low airflow, and (2) to determine whether a system is operating significantly outside of its rated performance. The former can be accomplished by measuring airflow using standard duct leakage measurement equipment and measuring static pressure in the supply and return plenums. The latter can be done by measuring return air and supply air dry bulb temperatures and return air wet bulb temperature to determine both the expected (target) temperature split and the actual temperature split. He indicated that, when done in conjunction with a duct leakage test, these tests add less than one hour to the procedure.

The following additional verifications can be completed by a home performance contractor without the need for refrigerant systems certifications and training:

- Verification of system operation: Are the fans and compressor running?

- Is air supplied to all registers?

- Condition and size of filter: Is the filter in good condition and is the air velocity less than $200 \mathrm{fpm}$ ?

- Is duct leakage less than $15 \%$ of system $\mathrm{cfm}$ ?

- Is the quality and thickness of duct insulation reasonable?

- Is the condensing unit coil plugged with debris?

- Is the vapor line insulated and is the TXV bulb properly secured and insulated?

David then explained that there is a lack of systematic refrigerant system diagnostic procedures that can be used to discriminate among the range of possible faults that only require the accurate 
test equipment that should be carried by every HVAC technician. Then, he presented examples of refrigerant diagnostic aids that are currently available.

View presentation: Manual Field Maintenance and Diagnostic Methods

\section{Discussion}

A question led to the discussion of the need certification of quality control (QC) programs. John said BPI and a North Carolina organization are talking about doing independent field inspections that could aid QC efforts. The point was made that if we can't count on HVAC technicians or home performance contractors, we are doomed.

\subsection{Codes and Standards}

\section{Application of ACCA Standards to Programs-Marshall Hunt}

Prior California HVAC maintenance programs have met with mixed success, generally falling short of deemed savings. Marshall described PG\&E's new program, which couples ACCA Standard 4-based quality maintenance with service agreements, and discussed the research that supports the program (PG\&E 2012). The program will initially target single-family detached and duplex units, and it includes a comprehensive suite of program elements that address barriers including marketing, IT tools, training, and incentives. Incentives can be as high as $\$ 850$, but $\$ 400$ is typical.

The program applies a three-step approach in which the first step is inventorying equipment, assessing the system, and delivering recommendations for repairs or renovation. In the second step, maintenance is provided to repair ducts, restore airflow, clean coils, and test and service the refrigerant system. Options also include replacement of blower and condenser fan motors. The third step is to facilitate a service agreement that provides for twice-yearly checks that apply ACCA 4 methods, and a report to the customer describing before and after results. ACCA 4 ensures that pressure imbalances resulting from air sealing do not degrade combustion safety.

To address the problem of incorrect diagnosis, the program uses SA Mobile digital diagnostic tools. The SA Mobile system calculates four indices that are used to evaluate a system's performance, including evaporator saturation temperature, superheat, condenser over ambient temperature (COA), and subcooling. Working with Robert Davis, they ran more than 200 situations through the SA Mobile system and got correct diagnoses. The program cannot currently diagnose non-condensables, but it uses a multiple metric fault diagnosis that helps catch all faults but needs to apply iterative process. They plan to constantly improve and build on their existing process. The SA Mobile procedure also verifies that filter friction values are consistent with ACCA Manual D, or not more than 0.1 in. w.c. at $400 \mathrm{fpm}$. California is the only state running this kind of program. Data are coming out of SA Mobile tests that started a year and a half ago.

View the presentation: Residential HVAC Quality Maintenance 


\section{Title 24 Methods and Changes-Tav Commins}

The California Energy Commission (CEC) is introducing changes in 2013 and 2016 codes that will include new measures and will better define what will be required of HERS raters and inspectors. The CEC has many reports that support code changes but it is impossible for staff to review all of them and must focus on specific measures that are brought to them and properly documented as potential code changes. It is important to have cheerleaders that can bring information to the CEC to help them understand the value of proposed measures.

There are currently no mandatory measures for HVAC systems. For the 2013 residential code, all new systems installed in existing or new buildings will require duct testing and airflow and fan watt draw measurements. Contractors may opt to use prescriptive duct and return grille sizing tables in lieu of airflow and watt draw measurements. There are fourteen HVAC measures for new homes, but only duct testing, charge verification, and airflow and watt draw for existing homes.

The process for selection of measures is generally that the Title 24 consultant determines what HERS measures must be applied. The responsibility for verification falls on the building officials, but it is difficult for them to understand what is in the forms and what is being applied. The CEC has provided training for building officials but it isn't well attended. The only way to ensure that specified measures are properly applied would be for the CEC to take over the job for the building departments, which will not happen. The CEC has worked with the Contractors State License Board (CSLB) to improve enforcement.

Tav acknowledged there are lots of problems with accuracy of gauges, lack of proper fittings, technician understandings of what needs to be done, the limited amount of time they want to spend, and their lack of knowledge of proper procedures. Some just fill in the numbers without testing. He would like to see the CSLB certify and track techs. He believes that anything that can be automated should be, such as ensuring a minimum 15-minute runtime before measurements are taken. Weigh-in charge doesn't work because third party coils don't list refrigerant capacity, and they have about $90 \%$ of the market. They are looking at changes that would provide specific Air Conditioning, Heating and Refrigeration Institute (AHRI) ratings for each coil and condenser pair. He is aware that DOE is working on a database but he doesn't know when it will go into effect.

For the 2016 standards, the CEC is considering factory-installed FDD on compressors as a compliance option. As the market adopts them and the approach is verified, they could turn into a mandatory measure. They are also considering making demand response thermostats mandatory.

[No presentation]

\section{Discussion}

Responding to Robert Mowris' comment that a minority of ACCA 4 items are not related to efficiency, Marshall Hunt replied that using the standard helps deal with market barriers and the work can be incorporated into service contracts. 
Marshall indicated that the SA Mobile software is only available to participating contractors, but FDSI has a generic version that is widely available. They are not collecting efficiency information, only ACCA 4 data. They specifically don't want to produce estimates of savings as it is not possible to measure EER at reasonable level of accuracy. If certain kinds of data are needed, they could be made available to the Building America Program.

\subsection{Training Community College HVAC/R Training-Jonathan Zeh}

Jon is department chair of the Mechanical-Electrical Technology Department (MET) at Sacramento City College. Their program is primarily oriented toward commercial training but also covers residential. They offer one- and two-year programs, with the two-year program including an MET certificate. The first year covers residential HVAC, including electric fundamentals, and training for the EPA certification exam. Gas-fired equipment and ACCA Manuals J \& D are taught in the second year. They also teach hydronics, which they believe will become more relevant as houses become tighter.

Jon described their teaching facilities and programs. They have air conditioning, refrigeration, furnaces, boilers, controls, and several other labs and a considerable amount of equipment used as training aids. Students spend more time in labs than in lectures and are trained in theory as well as practice. For example, students can experience the effects of duct sizing and equipment response to various failure modes such as coil freeze-ups. Training includes commercial direct digital controls (DDC), which are becoming relevant to the residential market as manufacturers introduce digital controls.

They have a very comprehensive and demanding program, and they have to continually introduce new material to individual classes without increasing the length of the program. They rely on outside training through utility programs to help fill in the new technology gaps. Jon feels that students should have some time in the field before they move on to learn more. He is glad to hear what is going on in the industry and with codes and standards because these new requirements make his students more in demand, therefore employable. His takeaways from the meeting are to invest in more diagnostic equipment and incorporate more information about Title 24 codes in the curriculum.

View the presentation: Mechanical-Electrical Technology (MET) Department

Review the course offerings in the MET catalog. $<$ link $>$

\section{Utility Training Programs-Gary Fagilde}

Gary works with the PG\&E Stockton Training Center, which is funded by the California Public Utility Commission (CPUC) with public goods charges. They provide training for those who have learned the basics and want to enhance their expertise. He reviewed the Training Center's class offerings, which are comprised of nine courses dedicated to HVAC and include training in ACCA quality installation, Manuals J, D, and S, airflow and pressure diagnostics, and NATE exam preparation. Other courses are provided on building performance and creating "the perfect building." The Training Center encourages hands-on exposure to equipment in their wellequipped lab, and they have a small house on site in which proper installation can be demonstrated. 
Classes are updated yearly to keep up with changes in California's energy codes. The Center also works with trade unions under the Workforce Education and Training program of the CPUC, and partners with community colleges.

Review the PG\&E Stockton Training Center class list.

\section{Discussion}

A comment was made that some classes teach to best practices while others teach to worst practice, in other words, whatever the code will allow. Jonathan noted that it's good to strive for a perfect world but we live in the world of reality. The quality of the work and performance goals depend on the values of the firm you are working with. We need to figure out what motivates people. David Springer asked if it is possible to teach quality. Jonathan responded that some students comprehend it, and some absolutely don't. He sees the whole spectrum from those who are focused and dedicated to those who have a very hard time. Their top students gravitate to the more stable commercial HVAC field. In the residential arena, key questions are: how much time will employers allow for training and what motivates the contractor to achieve excellence and the homeowner to demand it. "Contractors always make money", and if the conventional wisdom is that maintenance of a 5-ton package unit is worth $\$ 80$, then contractors will add whatever margins they need. Certification doesn't help if the contractor only allows the tech 20 minutes to do the work. Contrary to commercial building owners, homeowners have the awareness that their systems will only last about 10 years and therefore, like refrigerators, it is not worth investing in their upkeep.

\subsection{Contractor Perspectives HVAC Contractors-Bob Radcliff}

Bob Radcliff is with Beutler Corporation, a leading contractor serving many of the production builders in Northern California. Bob provided several facts about the realities of his industry. Beutler provides services that include new home HVAC installations and warranty service, as well as plumbing, fire sprinklers, and electrical. Last year Beutler had 300 employees and 25\% of their work force had been with them for one year. With the increase in new home activity, they have increased to 680 employees so far this year. In 2007, they were hiring 50 per week, but since the recent market recovery they need to relearn how to hire. Bob said it is a tremendous challenge finding trained technicians willing to work at the pay level they can afford to provide to stay competitive, and it is very difficult to find new raw talent. They were able to hold onto a core staff of trained people through the seven-year slump in the economy, but they had to put in a lot of overtime and are now helping to train the new hires. They are lucky if the "newbies" have heard of air conditioning.

Bob is finding that builders are increasingly opting for more efficient equipment (90+ AFUE furnaces and up to 15 SEER air conditioners) and that their purse strings are not as tight as they were. In reference to the information presented during the meeting, he said it was staggering but clearly what's needed. He's seeing some manufacturers like Goodman-Amana and Carrier offer communications that automatically set airflow based on the size of the connected air conditioner and built-in diagnostics, but at a significantly higher cost. However, this equipment can save time and eliminates the need for the tech to make programming decisions. Carrier posts diagnostic results on the thermostat, and he believes this is the right approach. He noted that the 
new generation of smart phone-literate technicians love to play with these devices, but they can also become a distraction and they tend to overlook a holistic view of the system.

With respect to training, Beutler had 230 employees going through an in-house, non-union, 3year apprentice program, but the program was limited to sheet metal and was non-technical. This program was abandoned when the housing market crashed. Beutler has two trailers that the company takes to high schools to help train students on system installation.

[No presentation]

\section{Home Performance Contractors-Mike McFarland and Dan Perunko}

From the vantage point of small home performance contractors that offer comprehensive retrofit services, Mike and Dan shared quite a different picture. Mike MacFarland of Energy Docs Home Performance and Dan Perunko of Balance Point Home Performance operate similar businesses bringing home energy upgrades to individual homeowners on a relatively small scale. They also help train others in their craft through their leadership of the annual Forum On Dry Climate Home Performance and participation in EEBA. They set a very high bar, and have formed a fraternity for others of like mind called the Ring 4 Club, which refers to the size of the DuctBlaster ring that had to be specially designed by Energy Conservatory to measure the leakage rates that they customarily achieve. They strive to outdo HVAC manufacturers' performance specifications by applying the following performance targets as follows:

\section{Ducts and Airflow}

- "LO" or at least less than $25 \mathrm{cfm}_{25}$ leakage

- R8 crawlspace systems and R20 attic systems (deeply buried)

- Room by room airflow

- Balanced to within 10\% of Manual D (or similar design), supply outlets sized for velocity, distance (throw) and noise, room pressures $<3 \mathrm{~Pa}$

- AC system airflow (CA dry climate) 500-600 CFM per ton

- Heating airflow $=$ Cooling airflow.

\section{Refrigerant Charge and TXV}

- Subcooling per manufacturer's low target

- Superheat less than $10^{\circ} \mathrm{F}$ or low manufacturer's target

- Adjustable TXV's to allow full control of superheat.

\section{Equipment Capacity}

- De-rate Manual J calculations by $20 \%$ to $60 \%$

- Lower than specified in Title 24 calculations by $50 \%$ to $70 \%$.

By applying these measures and others they reduced air conditioner size by an average of three tons per house over 35 homes. They carefully measure performance (test in and test out) and 
track energy bills for three years on every project. Using an "HVAC System Dynamometer," Energy Docs showed how they can provide distribution efficiencies of $92 \%$ (compared to $48 \%$ in an example they presented) and sensible heat ratios of $94 \%$. They deliver high airflows to reduce unnecessary latent cooling, and reduce fan energy use and improve efficiency by using indoor coils that are oversized by about a ton. The higher airflow results in about a $20^{\circ} \mathrm{F}$ temperature split, which provides more even temperature distribution.

To reduce duct static pressure, they stretch the ducts out to their full length and use rigid fittings wherever there are sharp bends. Using these methods and correct sizing, they have demonstrated $75 \%$ decrease from the T-24 allowable fan energy use.

They also set controls to provide for the fan to operate after compressor shutdown. After 15 minutes of overrun, they can still see a 6 degree split, but 5-7 minutes seems optimum. This strategy recovers energy from the coil and in cooling mode re-evaporates condensed moisture. Super insulated houses are sized at $1500-2000 \mathrm{ft}^{2}$ per ton, and no manufacturers make furnaces small enough. In those cases they use hydronic heating instead of furnaces. They strive for uniform airflow in heating and cooling modes, and maintain a constant airflow even with twostage equipment, so that grille sizes that are engineered for cooling work the same in heating mode.

The arguments offered by Mike and Dan support the full replacement of systems in most cases, as opposed to conducting remedial maintenance, because systems are generally poorly designed and installed and/or in poor condition, and because the measures they implement reduce loads to the extent that existing equipment is greatly oversized. In addition, most attics are insufficiently sized to permit the necessary duct sizes to deliver the proper dry climate airflow requirements per ton of AC. Only if they find that an existing system can be modified to meet their criteria for homeowner outcomes (comfort, airflow, etc.) will they not replace it.

Since they offer energy bill guarantees, what drives and motivates their firms is to ensure that they don't have to pay out on those guarantees. The guideline they follow, originated by Rick Chitwood (a PG\&E Stockton Training Center trainer), is that it should not cost more than $\$ 0.25$ per square foot per year to heat and cool a building in PG\&E service territory, and this rule has been working for them over the past seven years.

View the presentation: Contractor Perspective: Repair or Replace?

\section{Discussion}

Hung Pham noted that furnaces are commonly oversized in the Northwest. They see a low temperature split because airflows are higher than necessary due to the furnace sizes. Equipment is rated at an indoor relative humidity of $52 \%$ yet they find houses are around $40 \%$ and there is about a $7 \%$ degradation in efficiency due to the unnecessarily high latent capacity.

There was discussion about the longevity of flex ducts and some stories shared about problems with collapsed ducts that accompanied slides showing animals residing in flex ducts, and a question about whether they advocate use of sheet metal ducts. Dan and Mike agreed that where velocities are high because of limited space, or where ducts would not be accessible for replacement, rigid sheet metal ducts should be used. 
Responding to a question about how bad systems can get, Mike referred to a house that was losing more heat than was delivered. Iain Walker said they found one that was heating the house with attic air in cooling mode, resulting in a negative distribution efficiency.

Robert Mowris commented that replacement air conditioners are almost always the same size as the original systems, and suggested Mike and Dan take their show on the road and demonstrate what can and should be done to the CPUC because that is the kind of program California needs for quality improvement (QI). He also suggested that the sizing problem can be solved by keeping the large condenser coil and replacing the compressor with a smaller one and installing an efficient fan blade.

\subsection{Manufacturer Perspectives Factory Installed FDD-Hung Pham}

Hung Pham is with Emerson Climate Technologies, which manufactures Copeland compressors. Hung agreed with Dale Rossi that developing and introducing FDD into the market is a long, challenging road. Emerson's approach is to focus on detecting conspicuous gross faults rather than attempting to achieve minor faults prediction perfection, but it is developing more predictive capability for tracking faults earlier. He stressed the importance of understanding the value chain and how to accomplish broad adoption. Homeowners will not drive demand for FDD because they have no way to gauge energy use and have no awareness of the baseline. Emerson has been conducting field tests of products using 50+ of their own employees, and they found the homeowners don't know how to relate system performance to savings, and this creates a challenge for anyone who is trying to improve efficiency.

Contractors focus on assuring comfort and reliability to their customers as opposed to energy savings. As pointed out by other presenters, good contractors are in the minority and the industry has no mechanism for rewarding them. Hung feels it is better to lead by example than to expect that training will solve the problem. They have been offering embedded FDD products for 12 years but they have only about 5\% share of the residential market (adoption by the commercial market is much higher). They have found that even though they identify a fault, they sometimes couldn't call homeowners until the problem becomes more severe and critical because homeowners perceive the call as an effort to sell services they don't need. Homeowners expect their systems to last 20 years and don't understand why they are being told they need a new one unless they have repaired it too many times. They must rely on homeowners to judge the severity of the problem.

Hung presented a curve that moves from a green region of baseline performance to a yellow region of high energy use, and to a red region where the compressor is operating out of its envelope as indicated by long run times, compressor trips, etc. Emerson is focusing on the red zone where they will get the best bang for the buck, where they can detect major faults such as very low charge, very low airflow, frozen coil, and serious condensing unit faults.

Emerson produces two "CoreSense" FDD product types for outdoor units, one that wires or communicates to the thermostat so the homeowner knows there is a problem, and another that doesn't have to be wired and is just there in the outdoor unit for the contractor's use by either reading its blinking LED alert codes or by plugging into its data communication port with a Laptop or smartphone interface. They are thinking about developing a version that feeds 
information into the cloud. Both detect system and electrical faults by monitoring compressor current and run time and track trip patterns of compressors. Long continuous run time is good indicator of low charge since it is expected that systems will be off 6-7 hours over night. A 30\%$40 \%$ low charge will cause the compressor to run for longer cycles, but homeowners aren't typically aware this is happening. Daily kWh per day varies considerably (about $20 \%$ ), moves with thermostat settings and other factors, and it is difficult to baseline.

Compressor failures are rare, and it is usually something else that is causing the compressor to appear faulty. Remarkably, $35 \%$ of the compressors that are returned are classified as "no fault found" (NFF). System original equipment manufacturers are providing longer warranties (as long as 15 years) making it more costly for both compressor and system manufacturers to deal with NFF returns. So the value proposition of FDD for Emerson is to avoid incorrect diagnosis. Hung said it is not the fault of contractors that this is happening because conditions can be confusing. They are looking at how to deploy more expensive technologies that take more measurements. Their cost for a pressure sensor alone is about $\$ 20+$, so they prefer non-intrusive sensors. He emphasized the market is extremely sensitive to cost but that a fraction of the market, such as high end contractors, may be open to spending more on FDD, noting it may take another 15-20 years to reach a broad mature market such as the field of automotive diagnostics has done.

View the presentation: Fault Detection \& Diagnostic (FDD)-A Compressor Manufacturer Perspective

\section{Replacement Refrigerants-Hung Pham}

Production of equipment using R-22 ceased in 2010 because of the relatively high ozone depletion potential (ODP) of R-22. The decreasing availability and increasing cost of R-22 is becoming an important factor in the equipment repair vs. replace question. Hung presented Emerson's perspective on replacement refrigerants for R-22. He related that other countries are more aggressive in adopting low global warming potential (GWP) refrigerants than the United States. While U.S. manufacturers have adopted R-410a for residential systems, China is moving directly to R-32 and Europe is banning anything with a GWP higher than 2500. R-32 has a lower GWP than R-410a and is lower in cost, but has a mild flammability (R-410a is a 50/50 mixture of R-32 and R-125).

Hung estimated that the current cost of $\mathrm{R}-22$ is about $\$ 7-\$ 8$ per pound. A check with an HVAC supply house showed the wholesale cost in Northern California is currently $\$ 14$ per pound.

Hung presented charts that show global regulatory phase-down activities of high GWP refrigerants in North America and Europe. Europe no longer allows R-22 to be used while the United States will allow limited use until 2020 and "A5" nations may continue limited its use until 2040.

Manufacturers like Emerson with Copeland brand compressors approve alternate refrigerants on a case-by-case basis. Considerations include safety (toxicity, flammability, working pressures), performance, economics, and environmental [Ozone depletion potential (ODP), GWP, and life cycle climate performance (LCCP)]. Performance and equipment-related considerations include the following: 
- Pressures, Temperatures, and Mass Flow: Minimize flow control change, superheat set point adjustment

- Capacity: Operating comfort at maximum ambient temperatures

- Reliability: Oil circulation and management \& discharge temperature

- Component Changes: Compressors, expansion device, filter driers, gaskets, o-rings, oil

- GWP: High GWP candidates may face future phase downs.

Reviewing Emerson's recommended replacement options, Hung indicated that the use of any HFC blend with mineral oil lubricants is not recommended, so oils used with R-22 should be replaced with POE blend. Oil return and lubrication is not proven for mineral oils with HFCs and they are not UL recognized. Emerson's guidance on the replacement issue was as follows:

- Replace system with an R-410A system

- If one must retrofit condensing unit, use R-407C with POE oil, which is approved by Emerson

- All other retrofit refrigerants must be approved on a case-by-case basis.

He also noted that the industry will be faced with HFC phase down in the future. Another lowGWP refrigerant that is being considered by manufacturers is $\mathrm{HFO}(2,3,3,3$-Tetrafluoropropene), which has a GWP that is comparable to $\mathrm{CO}_{2}$. It is mildly flammable, but can be mixed with other refrigerants to create blends with reduced flammability and low GWP. Hung believes that commercialization of low GWP semi-flammable refrigerants will not occur until 2018 because of safety standards, and building codes will take time to develop.

View the presentation: Residential HVAC Replacement Refrigerants-A Compressor Manufacturer Perspective

\section{Discussion}

Iain Walker pointed out that if systems are installed correctly in the first place, perhaps they shouldn't be touched. That's where the best value might be. But there are two challenges: for example, how to determine if the installation is correct (the QI standard is not working well); and more accurate measurement and lower cost diagnostics are needed. Hung commented that contractors frequently refuse to open evaporator coils because it requires the removal of a lot of screws.

When asked if manufacturers would be moving toward factory-charged single package systems and away from field-charged split systems because of refrigerant safety, he replied that he thinks the $70 \%$ residential market share that is owned by split systems would remain. 


\section{Answers to Research Questions}

Following presentations, questions and answers, and discussions, little time remained to develop specific responses to each research question. Therefore, the following answers were formulated from the presentations.

\subsection{Is FDD Worth the Investment and what is the Savings Potential?}

Energy savings and the costs for maintenance are dependent on the climate, occupant behavior with respect to thermostat settings, house loads, the condition of the system, quality of maintenance, and many other factors. There is not sufficient data to generalize about the energy savings potential, though laboratory analysis of multiple faults indicates that they can reduce the effective SEER by $67 \%$.

The best potential source of data on realized energy savings is from utility programs, but due to a variety of factors, California programs have struggled with achieving the same "ex-ante" savings as estimated by the "ex-post" projections (Hunt 2010). This result is more an indication of the shortcomings of the programs than the real savings potential. PG\&E's new Quality Care program that uses SA Mobile's FDD systems promises to do a better job of controlling quality and will improve tracking. Simple fixes to improve airflow, clean coils, and other low-cost measures have a very high cost-effectiveness potential, but require maintenance strategies that target these low cost, high impact improvements.

In cases such as the scenarios presented by Dan Perunko and Mike McFarland, the goal is to deliver comfort and indoor air quality. Where homeowners are willing to invest in improved comfort and health, energy savings could be considered a no-cost byproduct.

\subsection{How Effective are Available FDD Methods and what do they cost to Implement?}

Referring to embedded FDD systems, the CoreSense systems described by Hung Pham are readily available and could cost as little as $\$ 10+$ to install. They can either be provided from the factory or retrofitted by the contractor. As they are designed to identify major faults, they likely have a high impact on energy savings and certainly on occupant comfort. Without a method of communicating faults when they are identified, the systems appear to be more useful for diagnosing equipment failures after they have occurred as opposed to identifying them before they happen.

Portable FDD systems like Field Diagnostics' SA Mobile gather more data and are more expensive but much more precise than the low cost factory embedded systems, but at the present time they rely on utility programs to support their use. For example, PG\&E offers a $\$ 50$ incentive to offset the cost of the technician's time to complete diagnostic testing, and follows through with other incentives to correct identified defects. Training and quality assurance controls are also provided by PG\&E's Quality Care program, so the pitfalls described by Kristin can hopefully be avoided. Contractors are required to be trained and certified under the program.

Proctor Engineering's CheckMe! is a comprehensive diagnostic program that addresses incorrect refrigerant level, low airflow through the indoor coil, and duct system air leakage. The program combines the use of a tool, the HVAC Guide System Analyzer, with technician training and in- 
field support. The System Analyzer evaluates evaporator temperature split, superheat, and subcooling. Proctor used this program to determine that $57 \%$ of residential systems tested required repairs, and charge was corrected in $92 \%$ of the cases out of a sample of 8,873 units (Proctor 2002). In his presentation, John cited the direct support of field technicians as a key element in the success of his program.

Referring to manual FDD methods (i.e., not using diagnostic software or embedded systems), information is available that links measurement results to particular faults, but there appears to be no systematic way of discriminating one fault from another and identifying false indications. Systematic methods for diagnosing airflow and refrigerant faults were provided in the Measure Guideline developed by Davis Energy Group/ARBI (ARBI, 2013), but practitioners are not currently aware of the availability of this guideline ${ }^{1}$. The cost to implement this procedure should be under $\$ 100$ based on field evaluations of the time required to complete measurements and diagnosis, particularly if the diagnostic testing is completed at the same time as other work such as testing duct leakage. The effectiveness of the procedure depends on the standard of care and skill of the technician. From the presentation offered by Kristin Heinemeier, it is apparent that poor practices by the majority of technicians threaten any efforts to conduct accurate diagnoses. If Kristin's finding is representative, major changes in the industry are needed to correct this problem.

There have been multiple studies evaluating potential and realized energy savings, many of which are referenced in a document prepared to support California Title 24 standards for refrigerant charge testing (CEC 2011). Beyond this information, there is little data on the cost or cost-effectiveness of FDD and maintenance programs besides what has been determined through utility program evaluations, which so far has been uncertain or mostly unfavorable (Hunt, 2010). New programs such as PG\&E's Quality Care program may provide better information on the relationship between maintenance cost and savings on a large scale, which is badly needed.

\subsection{What Training is Needed for Effective FDD and is it Being Provided?}

Refrigerant systems are complex, and technicians must be knowledgeable about the accuracy of their test equipment, proper measurement and charge procedures, and have a detailed understanding of faults and their symptoms. There are ample opportunities for practitioners to receive excellent training through community colleges, Sheet Metal and Air Conditioning Contractors' National Association (SMACNA), NATE, and California utilities. As more information becomes available about test equipment accuracy and proper methods, this needs to be integrated into training curricula.

Based on Kristin Heinemeier's experience, the problem might be partly with insufficient training and the tendency to apply outdated rules of thumb, but the major problem is with quality of service. As suggested by Jonathan Zeh, technicians who are not conscientious cannot be taught to improve the quality of their work, and the better technicians find work in the commercial sector. Specialized training provided through utility programs and tighter verification of correct installation of new and replacement systems by HERS inspectors may gradually lead to improved FDD and maintenance practices. With the introduction of automated FDD devices,

\footnotetext{
${ }^{1}$ DEG/ARBI intends to update these methods using recently acquired information.
} 
training can be focused in their use, resulting in less guesswork on the part of the technician and more efficient and effective field practices.

With the rapid growth of the new housing market, contractors like Beutler Corporation cannot afford to wait for a pool of trained technicians to be developed and must do what they can to train their installers in the field. It is not essential that installers have diagnostic skills but they should be trained on proper test and measurement procedures, charging procedures that avoid introduction of non-condensables, and maintenance of equipment such as vacuum pumps. Inadequate training will lead to future problems that will require time consuming diagnostic testing.

\subsection{Are Codes and Standards Working?}

As most of the meeting attendees are involved in California-based businesses, utility programs, and training, the discussion focused on California's Title 24 standards. California is ahead of other states in terms of its mandatory requirements for HVAC installation and replacements. However, Tav Commins of the California Energy Commission acknowledged there are significant problems with compliance and verification. Some installers and HERS verifiers simply fill in the required forms without conducting the required tests, or falsifying the numbers. The CEC is enlisting the Contractors State License Board to exert more pressure on those engaging in dishonest practices. Restructuring the way HERS verifiers are paid may be necessary to correct this problem.

The 2013 standards (due to take effect 1/1/14) will add airflow and indoor unit fan and watt draw to current requirements for charge verification, and these changes should have a positive impact, both with respect to the quality of system installations, but also with installer awareness of the importance of correct duct and filter sizing for providing proper airflow.

ACCA 4 standards provide an excellent guideline and checklist for technicians to follow, though as was pointed out, a minority of the checklist items deal directly with efficiency. Based on Kristin's experience, technicians do not follow and may not even be aware of the standard.

Unfortunately codes and standards only address new homes and equipment replacements. There is currently no regulatory process governing HVAC maintenance, so the quality of maintenance will remain an ongoing problem that can best be addressed through carefully controlled utility sponsored programs. Such programs must pass cost-effectiveness tests before they are submitted with utility rate cases and approved by the CPUC.

\subsection{What are the Major gaps and how can they be Addressed?}

The overarching gap identified during the meeting was the low quality of care given to FDD and maintenance by technicians, including disregard of standards such as ACCA 4 and other best practices. The apparent causes include pressure from unscrupulous business owners and managers to maximize revenue by reducing time on the job without serving the customers' needs, lack of understanding of HVAC system fundamentals, application of obsolete practices, and use of poorly maintained and calibrated equipment.

The second major gap relates to the difficulty that contractors serving the new home construction market have in obtaining and keeping qualified personnel. The root cause is the highly 
competitive market HVAC contractors serve, which undervalues quality of work and training and encourages hiring of low paid installers. Production homebuilders are extremely cost conscious, and this competition starts at the top.

The following ideas are offered for addressing the problem of poor performance of technicians servicing existing systems:

- Quantify energy savings and costs through controlled application of specific FDD and maintenance programs over a large sample of homes to determine the value proposition

- Develop business cases for utility-supported maintenance programs as well as nonincentivized HVAC service to demonstrate to contractors that best practices can yield profits

- Update utility and other training programs to ensure that students are benefitting from the most recent knowledge on FDD, charge, and other maintenance procedures

- Use utility programs or other means to disseminate information to homeowners regarding the hazards of routine maintenance and to provide checklists that allow them to judge contractor performance

- Move toward requiring factory installation of FDD devices that inform homeowners of defects and that aid technicians in identifying them

- Encourage programs such as CheckMe! that have requirements for training and access to support

- Make information on initiatives such as those led by Dan Perunko, Mike McFarland, and other Ring 4 members more widely available to serve as models for quality and performance.

The following ideas could contribute to improving the quality of new installations and to reducing the frequency of service and warranty calls in new installations:

- Encourage community colleges, utilities, ACCA, SMACNA, and/or NATE to increase the volume and quality of training to increase the labor pool for contractors serving production builders

- Tighten standards but simplify compliance procedures to encourage and ensure high quality installations in new homes while increasing the revenue from HVAC installations so that hourly wages can be increased

- Restructure verification procedures and HERS rater compensation methods so that builders and contractors are not rewarded by cheating on compliance forms

- Provide examples to new homebuilders of the comfort, energy, and reduced callback advantages that quality HVAC installations can provide, and help them improve the visibility of comfort systems to their buyers

View the presentation: Wrap up 


\section{Summary and Conclusions}

This section summarizes presentations in each of the five topic areas. The five presentations in the first section of the meeting painted a somewhat dismal picture of the types of faults that are inadvertently introduced by contractors who service and install systems, the magnitude of their impact on performance, the lack of attentiveness of technicians to proper procedure and application of standards such as ACCA 4, and the failure of commonly applied protocols to correctly detect and diagnose problems. Adding to the problem is the lack of perception by homeowners that HVAC systems deserve the same kind of attention as they give their automobiles. On the other hand, the information presented demonstrated the tremendous potential for energy savings in existing homes, and the measure of improvement that can be achieved in new home installations.

For example, Robert Mowris' experience in the lab and the field led him to conclude the following:

- Common installation and maintenance faults can reduce EER* by $10 \%-55 \%$ and SEER* by $35 \%-59 \%$.

- Standard methods cannot differentiate non-condensables from overcharge or dirty condenser and restrictions from undercharge or low airflow.

- Moderate to severe faults exist in $13 \%-80 \%$ of units.

- Current standards do not require filter driers, proper evacuation, vacuum pump maintenance, or purging hoses before connecting to systems.

- Federal standards are needed for tools, FDD, and procedures to prevent contamination and improper installation and maintenance of HVAC units.

Newly installed and replaced systems are probably adding to the inventory of sub-performing systems. The labor force that is installing new systems does not have the training to comprehend the complexity of HVAC systems, faults that can occur, and their consequences. Even if they apply correct procedures, the tools they are using may lead to incorrect charge. There is no obvious remedy for this problem. It is clear that, despite the effort California has invested in developing verification procedures, there are still badly installed and commissioned systems. David Yuill's presentation infers that protocols designed for California's Title 24 may not be up to the job of avoiding airflow and refrigerant charge faults. Raters who are providing verifications are under pressure to falsify compliance forms to avoid increasing builder costs, and those that are honest may have difficulty finding work since they are paid by the builder. A different mechanism is needed that eliminates this conflict of interest.

Most raters do not have the same technical expertise as HVAC technicians and are not trained to understand charge measurements and their impacts on performance. Providing wider tolerances for superheat and subcooling targets may not be very detrimental to performance and could alleviate some of the pressure on verifiers, making it easier for them to honestly complete compliance documentation. 
Most contractors are only concerned about delivering comfort and the bottom line, not efficiency. This situation will get worse as the market recovers and contractors are called upon to increase hiring. The limited number of community colleges with good HVAC programs are not producing enough qualified technicians to meet the demand, and the better technicians are gravitating toward the commercial sector. Also, market forces are keeping wages down, and qualified graduates of technical schools and highly trainable high school graduates are not attracted to the residential sector. Utility training programs supplement community college training but tend to attract only the select few who have experience and who are interested in learning and applying best practices. In-house contractor training takes effort to establish and contractors are not sufficiently rewarded to provide it.

The insensitivity of system performance to minor deviations in refrigerant charge (especially for TXV systems) and airflow, problems with measurement inaccuracy, and the level of training needed for detailed diagnostics, point to the approach of detecting and correcting only problems that have a major impact on performance. These are problems that can be detected by home performance contractors if they have the right tools, such as the diagnostic method described in David Springer's presentation. Field technicians who are not equipped with the FDD tools used in programmatic work also need more effective tools for distinguishing between the various refrigerant system faults that can occur.

A major issue is the inability or unwillingness of service technicians to apply proper procedures, or even a subset of checks listed in ACCA Standard 4, when homeowners request service. This problem creates a significant missed opportunity to improve efficiency while providing homeowners with the comfort they expect. The answer could be to focus training on ways contractors could improve their business models by correctly identifying faults and giving them the tools to efficiently diagnose faults, as well as the tools to show homeowners what they can save if corrections are made. A change, even if gradual, to the conventional wisdom that the most money can be made by spending as little time as possible on the job site is sorely needed. Technicians will need to learn to educate and sell as well as diagnose.

Kristin Heinemeier shed light on the low standards of service technicians and their failure to apply methods that are anything close to ACCA 4. Conclusions she formed from evaluating the performance of a number technicians were that there is a need to elevate the perception of technical sophistication of HVAC service so that people will be willing to pay more for it, and that homeowners be given tools to make contractors more accountable. She suggested that homeowners should be given a report that includes the ACCA 4 Maintenance Task checklist with measurements described and listed, showing their value and what they mean. A template can be designed for this purpose that would be easy to fill out.

Utility programs that provide more detailed diagnostics such as PG\&E's Quality Maintenance program that uses diagnostic software will improve technician understanding of systems, allow better fine tuning of performance, and will provide the necessary monetary incentive to encourage contractors to participate. The program also provides for service contracts, and provided participating contractors are monitored closely, major faults can be identified and problems averted. Although it will take a long time for such programs to achieve significant market penetration, they could mushroom by demonstrating that there is a business case for doing the job right, with or without incentives, and will provide workforce training along the 
way. Such programs can capitalize on the increased comfort level that younger technicians have with technology such as SA Mobile's diagnostic system.

The importance of including contractor feedback and monitoring as program elements was made evident by John Proctor. This kind of oversight also serves to educate technicians and raise their standard of quality. It can be expensive but should yield long term benefits by creating a better trained, more conscientious workforce.

Another view is that technicians are victims of the HVAC business structure and are unfairly blamed for failures. There is a leadership gap at the higher levels that should be addressed. Programs tend to capture the top 5\% and incentivize contractors to find problems instead of encouraging them to perform quality maintenance on all systems.

The existence of a handful of contractors like members of the Ring 4 Club serve to set the standard for what can be accomplished and will continue to provide excellent service to a small segment of the market. Their example can be used to support both the technical and business case for best practices and can provide information that might eventually find its way into Title 24 standards. Mechanisms should be developed to reward these "tier 1" contractors. Dan Perunko advised there are probably only four such contractors in the state, and they are battling to compete with lower tier contractors. He and Mike McFarland feel that there should be more of a focus on results, and approaches that work should be de-coupled from what is required by codes and standards or programs. Best practices should be applied to the whole system, not just the HVAC equipment, and programs should be well enough funded to do the job right. They cited the Redding Electric program, which provides incentives of up $\$ 9,000$ for upgrades to homes and systems that reduce peak load as an example.

Iain Walker suggested that it may be wiser to ensure that systems are correctly charged initially and leave them alone. Field studies have shown that a sample of systems that were routinely serviced had more refrigerant charge defects and problems with non-condensables than a sample that had no maintenance. It is Robert Mowris' belief that "Every tech introduces noncondensables," and their presence is difficult to diagnose or measure.

Setting refrigerant charge correctly is difficult because of instrument error, and particularly difficult or impossible during cold weather because conditions are "off the charts". As an alternative, weigh-in methods can be used if the capacity of indoor coils are known, which they are when provided by the manufacturer of the condenser or heat pump. But third party coils are installed by most contractors because they cost less and their capacity is unknown. Requiring third party manufacturers to list the volume of refrigerant they hold or to supply them precharged would solve this problem. Research to determine just how much system performance would be affected if coil capacity is not definitely known, and tables listing typical capacities of coils of specific tonnage would also be helpful.

On the question of repair vs. replace, there are two ways to look at it. One is that there are many systems that are performing very poorly mainly because of duct air and thermal leakage, low airflow, dirty coils, undersized filters, and other obvious problems that can be cost-effectively remediated. Maintenance to the HVAC system can be justified by reduced energy bills and significant improvements in comfort, provided there is someone willing to do the work. 
Where there are such major performance problems with the air conditioner that either maintenance or replacement is warranted, replacement appears to be the best option. The replacement equipment will have a guaranteed higher efficiency and can be correctly sized to the load when there have been home improvements such as added attic insulation or replacement windows. The rising cost of R-22 and the cost and/or risk of installing a replacement refrigerant can be avoided. Also, California codes require airflow and fan watt draw verification and duct leakage tests when systems are replaced, which will correct problems that are inherent in most of the existing housing stock.

The approach taken by Dan Perunko and Mike McFarland is to almost always replace, because with proper improvements to the house and system made, the existing system will be oversized. Robert Mowris suggested that rather than replacing the outdoor unit, the oversize condenser coil can be retained and a smaller compressor installed. The complete energy upgrade is clearly the right way to go, but probably beyond the reach of most homeowners and/or difficult to sell.

Developers of on-board fault detection devices are making headway. The introduction of communicating devices that monitor compressors, similar to what Hung Pham described, should be a boon to service contractors since they will be able to monitor and repair systems before they completely fail rather than on the hottest day of the year. These can be installed at the same time that service for such items as failed contactors, capacitors, or blown fuses are dealt with. The effect would be to provide a more even flow of service and greater profitability and workforce stability. Smart contractors will install them at cost. The Title 24 requirement for on-board FDD in new systems is also a looming possibility in California.

The HVAC industry and stakeholders are attempting to tackle many of these problems. The WHPA recently released their roadmap to "Onboard and In-Field Fault Detection and Diagnostics." This document will hopefully provide technical guidance on the direction that policy makers must take to change the status quo. 


\section{Action Items}

The meeting participants and other interested parties will continue to pursue their individual goals related to residential systems FDD. The following action items will require supporting resources that have not been identified, except as noted.

1. Obtain a large sample of data that can be used to define the cost-effectiveness of residential HVAC system maintenance measures. Couple this effort with utility programs that provide incentives and that are likely to yield significant data. This undertaking will require development of accurate short-term test methods for measuring in-situ pre and post EER. (A Building America project was proposed to undertake a similar effort on a smaller scale but it was not selected for funding).

2. Use information from studies like that described above to develop a business case for quality maintenance.

3. Work with community college programs to add Title 24 compliance information and detailed residential FDD methods to their curriculum.

4. Disseminate information to homeowners to facilitate better maintenance of filters and other components, and checklists they can use when contractors are called upon to provide service. This could be promoted through local energy efficiency and green action groups and by utilities in billing mailers.

5. Encourage state and federal energy regulatory agencies such as the California Energy Commission and DOE to require factory-installed FDD systems.

6. Work with production builders to ensure they understand the value of quality HVAC installations, including homebuyer referrals and reduced callbacks. This can occur in conjunction with recruitment of builders for DOE Challenge Home certification.

7. Support efforts to develop California Title 24 compliance procedures that are simple yet provide improved compliance verification, and to eliminate conflicts of interest between builders and HERS verifiers.

8. Update the measure guideline on FDD and Repair/Replacement previously submitted by ARBI to include information obtained through the meeting, particularly with respect to the repair/replacement decision, and distribute to workshop participants and others. This will be completed by DEG. 


\section{References}

\subsection{Documents Referenced in the Text}

ARBI. 2013. Measure Guideline: Air Conditioner Diagnostics, Maintenance, and Replacement. Building America Program report available from:

http://apps1.eere.energy.gov/buildings/publications/pdfs/building america/measure guide air c ond diagnostics.pdf.

CEC. 2011. "Measure Information Template - Residential Refrigerant Charge Testing and Related Issues." Prepared for the 2013 California Building Energy Efficiency Standards under the California Utilities Statewide Codes and Standards Program. California Energy Commission.

Downey, T., and J. Proctor. 2002. "What Can 13,000 Air Conditioners Tell Us?" Proceedings of the 2002 ACEEE Summer Study on Energy Efficiency in Buildings. Washington, D.C.

Hunt, M., K. Heinemeyer, and M. Hoeschele. 2010. HVAC Energy Efficiency Maintenance Study. Project report prepared by Davis Energy Group for Southern California Edison.

Mowris, R., E. Jones, and R. Esham. (2012). "Laboratory Measurement of HVAC Installation and Maintenance Faults." ASHRAE Transactions v. 118 (2).

PG\&E. 2012. Residential Quality Maintenance Unitary Air Conditioner Fault Detection \& Diagnostics. Emerging Technology Project Number ET11PGE5261. Prepared by Marshall Hunt, PE and Robert Davis, PE. Available from: http://www.etccca.com/sites/default/files/reports/ET11PGE5261_11_30_12.pdf.

RASS. 2009. 2009 California Residential Appliance Saturation Study. CEC-200-2010-004. California Energy Commission. October 2010.

SCE. 2013. Laboratory Assessment of a Retrofit Fault Detection and Diagnosis Tool on a Residential Split System. Report HT.11.SCE.005. Design \& Engineering Services Customer Service Business Unit, Southern California Edison.

SCE. 2012a. Development of a Fault Detection and Diagnosis Laboratory Test Method for a Residential Split System. Report HT.11.SCE.003. Design \& Engineering Services Customer Service Business Unit, Southern California Edison.

SCE. 2012b. "Evaluation of the Effects of Common Faults on a Residential Split System". Report HT.11.SCE.007. Design \& Engineering Services Customer Service Business Unit, Southern California Edison.

(Note: All three of the above SCE reports are available at: www.etcc-ca.com/ - search key word "fault detection")

\subsection{Other Relevant References and Resources}

Aldrich, R., and S. Puttagunta. 2011. "Measure Guideline: Sealing and Insulating Ducts in Existing Homes." Consortium for Advanced Residential Buildings, Steven Winter Associates. 
http://apps1.eere.energy.gov/buildings/publications/pdfs/building_america/meas_guide seal_duc ts.pdf.

Blasnik, M., T. Downey, J. Proctor, and G. Peterson. 1996. "Assessment of HVAC Installations in New Homes in APS Service Territory." Proctor Engineering Group Report for Arizona Public Service Company.

Braun, J.E., H. Cheung, and D. Yuill. 2011. "Purdue University Update to the Western HVAC Performance Alliance AFDD Subcommittee -July 2011." Presentation relating to the project, Test Methods for Evaluating Fault Detection and Diagnostic Systems. www.performancealliance.org/Portals/4/Documents/CommitteeWorkspace/AFDD/Purdue\%20F DD\%20evaluation\%20update.pdf.

CEC. 2008. "Residential Field Verification and Diagnostic Procedures." Appendix RA3 to the California 2008 Title 24 Residential Energy Standards. California Energy Commission.

Kuonen. 2011. “Air Conditioning Best Practices." Home Energy Magazine, May/June 2011.

Maier, A., and M. Scancarello. 2009. "Polyolester Oils: Handling the New Lubricant in R-410A Systems." Air Conditioning Heating Refrigeration News, August 2009. http://www.achrnews.com/articles/polyolester-oils-handling-the-new-lubricant-in-r-410asystems.

Messenger, M. 2008. "Strategic Plan to Reduce the Energy Impact of Air Conditioners." CEC400-2008-010. California Energy Commission. June 2008.

Mowris, R., A. Blankenship, and E. Jones. 2004. "Field Measurements of Air Conditioners with and without TXVs." ACEEE Summer Study on Energy Efficiency in Buildings. August 2004.

Neme, C.; Proctor, J.;, Nadel, S. (1999). "Energy Savings Potential from Addressing Residential Air Conditioner and Heat Pump Installation Problems". Report Number A992, American Council for an Energy Efficient Economy.

Parker, D.; Sherwin, J.; Ranstad, R.; Shirey, J. (1997). "Impact of Evaporator Coil Airflow in Residential Air-Conditioning Systems", ASHRAE BN-97-2-1, ASHRAE Transactions 1997, v. 103, pt. 2.

Parker, D., J. Sherwin, and B. Hibbs. 2005. "Development of High Efficiency Air Conditioner Condenser Fans.” Publication Number FSEC-CR-1674-05. Florida Solar Energy Center. Cocoa, Florida.

PG\&E. 2001. "Influence of the Expansion Device on the Performance of a Residential SplitSystem Air Conditioner.” PG\&E Report No 491-01.1. Pacific Gas \& Electric Company. January 2001.

PNNL. 2011. Energy Renovations: HVAC-A Guide for Contractors to Share with Homeowners. Volume 14, Building America Best Practices Series, Building Technologies Program. Pacific 
Northwest National Laboratory and Oak Ridge National Laboratory. August 2011.

http://apps1.eere.energy.gov/buildings/publications/pdfs/building_america/hvac guide.pdf.

Proctor, J., R. Chitwood, and B.A. Wilcox. 2011. "Efficiency Characteristics and Opportunities of New California Homes." California Energy Commission. Sacramento, CA.

Proctor, J. 1998. "Monitored in-situ Performance of Residential Air-Conditioning Systems", ASHRAE Transactions 104(1): 1833-1840. Atlanta: American Society of Heating, Refrigerating and Air Conditioning Engineers, Inc.

Proctor, J. 1997. "Field Measurements of New Residential Air Conditioners in Phoenix, Arizona." ASHRAE Transactions 103(1): 406-415. Atlanta: American Society of Heating, Refrigerating and Air-Conditioning Engineers, Inc.

Siegel, J., and W. Wray. 2001. "An Evaluation of Superheat-Based Refrigerant Charge Diagnostics for Residential Cooling Systems.” LBNL-47476. Lawrence Berkeley Laboratory.

Springer, D. 2009. “Is There a Downside to High MERV Filters?” Home Energy Magazine, Nov/Dec 2009.

Temple, K., and T. Rossi. 2006. "Enhanced Refrigeration Diagnostics for an Improved Air Conditioning Tune-Up Program.” 2006 ACEEE Summer Study on Energy Efficiency in Buildings. American Council for an Energy Efficient Economy.

Wilcox, B., and R. Chitwood. 2010. “2010 California New Home Energy Survey.” Presentation at the 2010 EEBA Conference, Austin, Texas. April 22, 2010. 


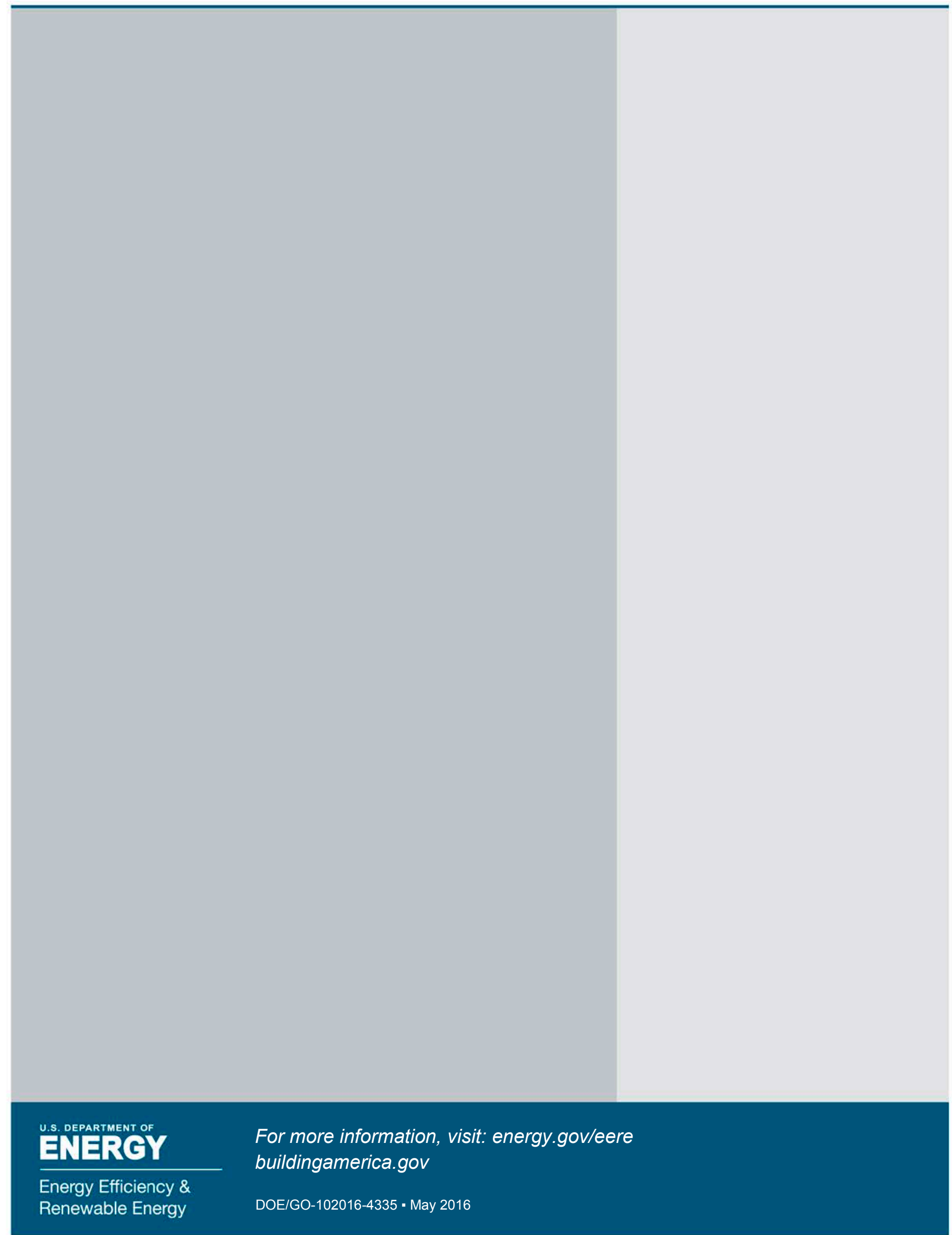

